\title{
THE CHANGING SOUL OF EUROPE \\ Religions and Migrations in Northern and Southern Europe [Helena Vilaça, Enzo Pace, Inger Furseth e Per Pettersson (orgs.), 2015, Farham, Ashgate AHRC/ESRC Religion and Society Series]
}

\author{
Maria João Oliveira \\ Centro de Investigação em Educação e Intervenção Comunitária (RECI), Lisboa, Portugal \\ Colaboradora no Instituto de Sociologia (IS), Porto, Portugal
}

Na senda de um expressivo crescimento dos fluxos migratórios e do aumento significativo da sua diversidade cultural, religiosa e étnica, as sociedades têm-se confrontado com muitos e novos desafios. Desde a forma como os estados são capazes de receber e lidar com a imigração, aos recursos que os imigrantes são capazes de mobilizar e ao papel de mediação que entre eles podem assumir determinados grupos ou instituições, muito se tem pesquisado e problematizado nesta área. Tal relaciona-se com a noção de que as migrações, enquanto processos de mudança social intersistemas de ordem, se apresentam como "situações críticas não só sobre a ordem interativa, mas também sobre o próprio habitus" (Pires, 2003: 50).

Neste contexto, o estudo da dimensão religiosa surge da consciência crescente, tal como Fenton nos alerta (2004), de que religião e etnicidade, embora distintas na realidade e analiticamente, estão intimamente relacionadas enquanto dimensões da identidade. A obra The Changing Soul of Europe. Religions and Migrations in Northern and Southern Europe, publicada em 2015, dá para este debate um contributo teórico e analítico relevante. O livro surge na sequência da conferência internacional "Local Diversity and Global Challenges. Religions and Migrations in Southern Europe", organizada em 2010 por Helena Vilaça, e de uma obra conjunta coordenada pela mesma autora e Enzo Pace (2010). O foco no sul da Europa, que em ambos os casos tinha recebido especial atenção, alarga-se com esta nova publicação aos países do norte da Europa, propondo-se os autores colmatar o que consideram ser uma lacuna entre as obras que têm sido publicadas: comparar, do um ponto de vista sociorreligioso, o impacto das migrações entre o norte e o sul da Europa (cf. Introdução).

A obra apresenta-se dividida em duas partes. Uma proeminentemente teórica que, para lá das teorias da secularização ou do desencantamento do mundo, nos introduz os desafios que enfrenta a própria teoria social na compreensão do fenómeno em análise. E uma segunda parte mais empírica, composta por nove pesquisas que resultam de trabalhos autónomos em diferentes territórios do norte e do sul da Europa onde se configuram os desafios sociais e culturais que estas sociedades enfrentam em resultado da crescente mobilidade geográfica.

Começamos assim a ser conduzidos pelo sociólogo Enzo Pace (capítulo 1), que recupera a teoria luhmanniana dos sistemas sociais por considerar útil compreender como, quando o ambiente muda, a sociedade deve aprender a transferir a sua complexidade externa em diferenciação interna. Uma mudança social que o autor revela estar a acontecer sob, pelo menos, quatro configurações e que denomina como os quatro cavaleiros do Apocalipse: the White Knight, the Red Knight, the Black 
Knight e the Black Knight. Uma conceptualização que para o contexto europeu ajuda o autor a explicar dois modelos de nação, um mais baseado na cidadania e outro na etnicidade, bem como a emergência das ideologias islamofóbicas e o risco de etnicização das diferenças culturais e religiosas.

Madureira Pinto, que tem a difícil missão de comentar os contributos de Pace e de acrescentar à discussão a dimensão económica do fenómeno (capítulo 2), começa por tecer uma interessante crítica às limitações das teorias económicas mais tradicionais e sublinha o papel que as redes e afinidades culturais, as políticas públicas, mas também a estrutura de classes e a condição social dos imigrantes assumem nas diferentes configurações sociais, a que Pace nos introduziu no primeiro capítulo. Madureira Pinto termina a salientar a importância do estudo do vetor da "lealdade" proposto por Hirschman, autor em que Pace também se inspira, mas ao qual deu menos atenção. Fazendo ligação com os contributos de Burawoy, para quem a religião também produz frequentemente conformidade das almas e dos corpos com o status quo, Pinto termina enfatizando que a "lealdade" não deve ser esquecida na abordagem sociológica do poder simbólico e político dos sistemas de crenças.

A dimensão política do fenómeno é trazida por Tuomas Martikainen (capítulo 3), num capítulo que encerra a primeira parte da obra. O autor, sem deixar de refletir sobre o papel dos imigrantes e das suas religiões no contexto de receção, debruça-se particularmente sobre a importância das implicações políticas para as condições sociais e as práticas religiosas das comunidades religiosas imigrantes. Elenca, nesse sentido, um conjunto de aspetos que contribuem muito especificamente, do meu ponto de vista, para compreender as singularidades e as diferenças entre o norte e o sul da Europa no que diz respeito às implicações sociorreligiosas da mobilidade geográfica. Nomeadamente, como é que - tal como se questiona na introdução da obra - , apesar de a religião de estado ter persistido até mais recentemente nos países do norte da Europa do que nos do sul, os níveis de secularização são mais elevados entre os primeiros. Exemplificando com o caso finlandês, o autor constrói dessa maneira a ponte para a segunda parte do livro, onde são abordados os estudos de caso.

Por conseguinte, no sul da Europa, são-nos apresentados: o caso grego, onde existe ainda uma igreja de estado e os direitos religiosos são limitados, apesar da liberdade religiosa; o caso português, onde há um estado laico mas a Igreja Católica continua a compensar as fragilidades do estado na esfera da ação social; e o caso italiano, onde se vive um "secularismo católico", como recupera Annalisa Frisina, com base no contributo de Pace noutro contexto.

Mais em detalhe, Elisabeth Diamantopoulou (capítulo 4) revela como, na Grécia, o ineficaz e desadequado enquadramento institucional da imigração contribuiu, entre outros fatores, para criar um ambiente frágil na gestão do fenómeno e, por isso mesmo, um contexto potencialmente explosivo, onde a Igreja Ortodoxa da Grécia é chamada a ter um papel decisivo, mas sobre o qual a própria se tem revelado particularmente crítica. Trata-se, portanto, de um claro exemplo da importância do contexto político de receção dos imigrantes, de que Martikainen nos falava anteriormente e que serve ainda para compreender o caso português 
apresentado por Helena Vilaça (capítulo 5). A autora demonstra como, embora se reconheça que as igrejas históricas possam não ser tão essenciais como no passado, a Igreja Católica portuguesa, mediada pelo seu Secretariado Diocesano para as Migrações, continua a orientar a vida dos migrantes das comunidades religiosas, nomeadamente das comunidades católicas de rito bizantino, nos mais diversos níveis: cívico, económico, afetivo, cultural, linguístico e religioso. Um contexto que não impede que outras denominações religiosas, com uma identidade religiosa menos próxima da Igreja Católica, gerem maior resistência. É o caso da Igreja Universal do Reino de Deus, explorado por Donizete Rodrigues (capítulo 7), cujo maior desafio, de acordo com o autor, é imposto por uma nova lógica de funcionamento em que as igrejas pentecostais agem de acordo com as regras de um mercado complexo e competitivo: o "mercado de bens simbólicos".

Em Itália, por sua vez, Roberta Ricucci (capítulo 6) coloca o foco da análise nos processos de identificação de uma segunda geração de imigrantes cristãos católicos (filipinos, peruanos e romenos). A autora conclui que o processo de aculturação sob o qual traçam a sua integração é mais forte do que a sua socialização religiosa, embora estes jovens permaneçam, em geral, entre uma situação em que continuam a ir à sua igreja e a procurar simultaneamente uma forma autónoma de pertença religiosa. No entanto, também as caraterísticas dos próprios imigrantes jogam aqui um papel importante, pelo que a situação para aqueles que não estabeleceram uma relação positiva com a sociedade italiana é diferente. São também os jovens que ocupam a centralidade do capítulo escrito por Annalisa Frisina (capítulo 9), em particular um grupo de jovens mulheres muçulmanas de Bolonha pertencentes à Associação Jovens Muçulmanos de Itália. A autora explora com estas mulheres a forma como se relacionam com o espaço envolvente, sublinhando que Bolonha é o exemplo de um contexto local muito particular, onde o pluralismo é publicamente reconhecido como um valor e as diferenças encontram legitimidade.

Deslocamo-nos de seguida para o norte da Europa, onde passamos a compreender melhor como na Suécia e na Noruega, onde os processos de separação entre a igreja o estado são muito recentes, mas também na Dinamarca, onde ainda existe uma igreja de estado, estas sociedades lidam com a diversidade cultural, étnica e religiosa. No primeiro caso, Anne Kubai (capítulo 8) observa como a igreja da Suécia ainda que em termos teológicos e discursivos seja muito inclusiva -, na prática instrumentaliza as congregações africanas, contribuindo para a inclusão de uns e a exclusão de outros, incentivando ainda a colaboração de algumas, mas deixando-as de fora em certos processos. Uma realidade que, do ponto de vista da autora, reflete alguma impreparação para lidar com estas igrejas imigrantes, apesar de reconhecerem a inevitabilidade do processo de mudança social subjacente. Está, no fundo, associado ao que Per Pettersson explora mais à frente (capítulo 10) e que remete para o facto de a igreja da Suécia manter um papel dominante no cenário religioso, apesar da separação entre o estado e a igreja e dos elevados níveis de secularismo. No caso da cidade de Gavle, que investigou aprofundadamente, o autor demonstra como os valores e práticas cristãos estão implícitos no quotidiano sueco, o que obriga a constantes negociações - também elas orientadas por valores cristãos - sobre os valores e, por conseguinte, sobre a mudança de práticas na esfera pública. 
Por sua vez, na Noruega, Inger Furseth (capítulo 11) retoma a importância da construção das fronteiras simbólicas que envolvem o uso do hijab entre muçulmanos e não muçulmanos e entre diferentes grupos de mulheres muçulmanas. Depois de discutir teoricamente com Michèle Lamont e Bourdieu, a autora descreve as diferentes formas de fronteiras simbólicas que observou em Oslo, concluindo que as fronteiras morais, culturais e geracionais são mais porosas do que as fronteiras religiosas para estas mulheres, sendo razoável, para a autora, assumir que o hijab dá à mulher mais estatuto e melhora a sua posição em alguns meios muçulmanos, mas que fora destes também pode funcionar de forma inversa.

Finalmente, Jorn Borup (capítulo 12) termina com uma pesquisa sobre os budistas e cristãos de origem vietnamita na Dinamarca, focando particularmente a análise nas caraterísticas dos imigrantes e das suas religiões. Entre outras variáveis, como a educação e a idade, o autor analisa o papel da etnicidade e da socialização na orientação individual e cultural destes sujeitos. De forma muito interessante, o autor incorpora na análise a multidimensionalidade do fenómeno, revelando que, embora existam diferenças de tipo e grau entre budistas e cristãos, a cultura de origem e a identidade étnica estão relacionadas com o grau de envolvimento religioso no contexto de diáspora.

Posto isto, a obra termina com uma reflexão sobre os principais conteúdos de cada um dos seus capítulos e uma visão de conjunto onde os autores enfatizam como desafio transversal às diferentes sociedades europeias a presença da religião na esfera pública. Do meu ponto de vista, não se pode dizer que o livro supere a lacuna comparativa que existe na abordagem das mudanças sociorreligiosas entre $o$ norte e o sul da Europa, que nos é dada sobretudo através da sua introdução e da interessante conclusão, mas contribui certamente para um aprofundamento da sua compreensão. Por outro lado, um estudo com espectro mais amplo de países ou territórios, pode pensar-se, teria enriquecido a análise, subsistindo no fim da sua leitura uma vontade particular de ter visto refletidas nesta obra as realidades francesa e espanhola. Todavia, e termino com uma observação que é menos paradoxal do que pode parecer à primeira vista, mais do que o foco territorial que dá o mote para este livro, o que mais enriquece esta obra são os múltiplos aspetos e dimensões subjacentes à compreensão das relações entre religiões e migrações nas diversas sociedades.

\section{Referências bibliográficas}

Fenton, Steve (2004), "Modernidade, etnicidade e religião", em Donizete Rodrigues (org.), Em Nome de Deus. A Religião na Sociedade Contemporânea, Porto, Edições Afrontamento, pp. 51-75.

Pires, Rui Pena (2003), Migrações e Integração. Teoria e Aplicações à Sociedade Portuguesa, Oeiras, Celta Editora.

Vilaça, Helena, e Enzo Pace (coords.) (2010), Religião em Movimento. Imigrantes e Diversidade Religiosa em Portugal e Itália, Porto, Estratégias Criativas. 
Maria João Oliveira. Investigadora no Centro de Investigação em Educação e Intervenção Comunitária (RECI), Viseu, Portugal, e colaboradora no Instituto de Sociologia (IS), Porto, Alameda Jean Piaget, no‥ 100, apartado 1523, 4411-801 V. N. Gaia, Portugal. E-mail: maria.joao.oliveira@hotmail.com 
